\title{
Engaging Conversationally: A Method for Engaging Students in Their Learning and Examining Instruction
}

\author{
Michael Kiener PhD, CRC \\ Assistant Professor, Rehabilitation School of Health Professions \\ Maryville University
}

Under the principles of the scholarship of teaching and learning and action research this study sought to examine how an instructor created and facilitated engagement in his students. The research was primarily undertaken to further define the middle range theory of mutual engagement. Theoretical sampling was used to analyze approximately 100 pieces of data that included instructor notes, teaching observations, feedback from conference presentations, student assessments, and end of semester student evaluations. Engaging conversationally (EC) emerged as

the phenomenon that described the instructor's engagement in the learning

process. EC was an ongoing cyclical pattern of inquiry that included preparing, reflecting and modeling. Interconnected in the pattern of inquiry were personality traits, counselor education, and teaching philosophy.

Determining optimal conditions to create and facilitate student engagement is a question basic to education. Examining educational research under the terms classroom community (Hirschy \& Wilson, 2002; McKinney, McKinney, Franiuk, et al., 2006; Rovai, 2001), active and dynamic learning strategies (Ahuna \& Tinnesz, 2006; Tinnesz, Ahuna, \& Kiener, 2006), advisory working alliance (Schlosser \& Gelso, 2005; Schlosser \& Gelso, 2001), cognitive development (Schrader, 2004), and reflective practice (Koch \& Arhar, 2002; Koch, Arhar, \& Wells, 2000), one will find a common theme; engagement in learning has beneficial outcomes. Broadly conceptualized, student engagement can include factors that increase learning such as teaching and learning styles, interactions between students and students and instructors, student ability to internalize learning processes, matching student cognitive development, and student ability to become a life long learner. Simply, engagement can be seen as the processes the student and instructor undertake to maximize understanding.

Perhaps conceptualizing engagement as an outcome of the scholarship of teaching and learning will provide its greatest value. Over the past fifteen years, increased attention has been placed on expanding scholarship to focus more completely on all aspects of academia. The scholarship of teaching and learning encourages teachers to make their practice public and to question
The scholarship of teaching and learning encourages teachers to make their practice public and to question their practice. their practice. Huber and Hutchings (2005) stated the scholarship of teaching and learning allows instructors to research "how best to engage students in learning that matters, and how to help them put pieces together to find meaning in their college careers" (p. 2). When instructors research engagement in their classrooms, not only can they validate what works best for their students, but they also model how to think critically about their practice and make changes based on their observations.

Although engagement has been studied from multiple perspectives, there is a further need to investigate how instructors facilitate engagement. Equally important is researching the process of systematically studying teaching to promote engagement and professional development (Grushka, McLeod, \& Reynolds, 2005; Kraft, 2002; Magnuson \& Norem, 2002). One can argue that systematically studying one's teaching implicitly involves instructor engagement. It is feasible to believe that a critical analysis of teaching and engagement would lead to a better understanding of teaching and learning. Moreover, Kiener (2007) called for the need to further examine engagement as a pedagogical tool and the impact that systematically studying teaching has on instructors. 
One method to address these questions is with action research. Action research is a method of inquiry specifically designed to involve teachers in their educational decisions to improve practice (Corey, 1952). The use of action research to investigate one's teaching is not new and has found prevalence in teacher education. Action research can be thought of as a meta-methodology that corresponds well with the principles of qualitative research-studying phenomenon in the context in which it occurs (Heppner, Kivlighan, \& Wampold, 1999). Action research allows teachers to investigate issues that directly impact their practice and make decisions based on their findings (Llorens, 1994).

It is plausible to believe from a systematic investigation of teaching that a deeper understanding of how to facilitate engagement as a pedagogical tool can be revealed. The overall purpose of this research was to make teaching more explicit and open to critique by investigating how an instructor facilitated a classroom atmosphere of engagement in learning and the use of

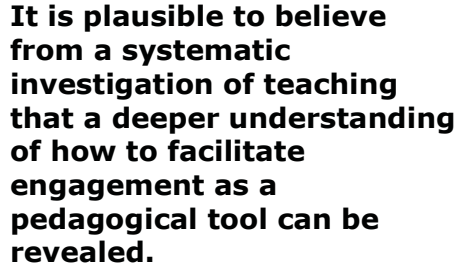

engagement as a pedagogical tool. Secondarily, this research was conducted to gain a deeper understanding of a grounded theory study that found mutual engagement as a core category of student learning (Kiener, 2007). The specific research questions were: (1) how can an instructor facilitate and sustain an atmosphere of engagement; and (2) how can engagement benefit pedagogical development?

\section{Methodology}

A qualitative approach to data collection and analysis was chosen due to its applicability in answering the research questions and its ability to gain a deeper understanding of the phenomenon of engagement. The research was primarily undertaken to further understand engagement; therefore, theoretical sampling, as described by Strauss and Corbin (1998) and Glaser (1978) was used as the primary sampling technique used to collect data. The purpose of theoretical sampling is to further define a core category (the term used to describe the main phenomena that emerged from the data) and to interconnect it to minor categories by asking critical questions of the data. Previous data is reanalyzed and future data is collected based on questions asked of the data (Jezewski, 1995). The end result is a more developed theory (middle range, substantive, or formal). In addition, a constant comparison method of data analysis was used, also described by Strauss and Corbin (1998) and Glaser (1978). Through this process, collected data were constantly being compared to recently collected data to develop categories and their properties and dimensions. Properties of a category can be defined as "the general or specific characteristics or attributes of a category"; whereas, "dimensions represent the location of a property along a continuum or range" (Strauss \& Corbin, 1998, p. $117)$. What results is a core category that emerges from the data that captures the experiences of the participants.

\section{Data and Participants}

There were approximately 100 pieces of data collected and analyzed throughout the semester that included instructor planning and process notes focusing on each of his classes taught, written observations of his teaching, feedback from conference presentations, student narratives, and end of semester student evaluations. The study was presented at two conferences, reviewed by two action research and qualitative researchers, and employed member checking to ensure triangulation of the data.

Due to the principles of action research, the main participant of the study was the instructor. The instructor studied all three of his classes being taught during 
the research process. The classes included a foundation, internship, and counseling theory course. Class size ranged from 5-15 students; there were 30 total students, 24 of them were different and 23 agreed to participate. In addition to varying in content and size, the courses were at the beginning and end of the curriculum. Furthermore, faculty in the author's program and the Dean were invited to describe what engagement looks like to them and what they do to engage their students. One faculty member and the Dean agreed to participate. All of the participants added a unique perspective and contributed to a deeper understanding of the research question. Several times throughout the study, the participants were sampled to gain their perspective of the research questions. Sample questions asked of the participants included: (1) What does engagement in learning look like to them; (2) how are they actively engaged in their learning; and (3) what is the instructor's and the student's role in learning.

\section{Findings}

A preliminary grounded theory study found mutual engagement and comfortability in the learning process core categories and conditions in which learning occurred (Kiener, 2007). The current study continued to examine the phenomenon of engagement in the learning process and was conducted to further define its relevance and applicability as a middle range theory. Theoretical sampling of the data found engaging conversationally (EC) as the phenomenon that described the instructor's engagement in the learning process.

\author{
Theoretical sampling of the \\ data found engaging \\ conversationally (EC) as the \\ phenomenon that described \\ the instructor's engagement \\ in the learning process.
}

\section{Engaging Conversationally}

Engaging conversationally was achieved through balance. Balance with pace of speech, discussions with the class, structure of class (lecture, video, learning performances, guest speakers, etc), physical movement, and ambiguity of class interaction (allowing for student disclosure while staying connected to the entire class). Four written observations illustrate engaging conversationally. The instructor "responded well to the questions and comments raised by the students while managing to keep the discussion focused on the original topic."; "Pacing was comfortable. Not too slow nor too fast. Comfortable enough to take questions in the middle and not bothered by them. Treated audience like 'old friends' who were interested." (faculty comments; conference evaluations); "Meeting and accepting the students where they are at. Believing the group has resources within to address the developmental tasks they face to mature as counselors."; "The philosophy of teaching: very informative, stimulating, humor, respect, thorough explanation of material." (student comments). As demonstrated from the data, EC was a balance of the instructor's teaching style. The specific characteristics of EC remain unclear.

Further examination of EC revealed observable traits of preparing, reflecting, and modeling the teaching process. Preparing included studying and implementing pedagogical frameworks and the use of course management tools (WebCT). For example, the Teaching for Understanding framework (a pedagogical framework by Harvard's Project Zero) of generative topics, understanding goals, performances of understanding, and ongoing assessment heavily influence the author's teaching (Blythe \& Associates, 1998). Preparing for a class with pedagogy in mind provides a foundation and rationale and allows instructors to assess student understanding (instructor planning notes). Course management tools provide a means to stay organized and connected with students outside of class. Examples of preparing, from the data, included posting resources on WebCT and making connections with the material to multiple courses. The following quote from a 
faculty member accurately captured one aspect of preparing when asked how to engage students:

"I provide a written statement to my students at the beginning of each semester, the statement provides what I expect of students and what they can expect of me. I seek as many outside resources as possible, stay involved in the profession, challenge my thinking through dialogue with others, and study" (B. Parker, personal communication, October 24, 2006).

It is feasible to believe that one aspect of student engagement is actively and systematically preparing for instruction; however, it is also feasible to believe that more is needed to optimally create and sustain meaningful student engagement.

The second component of EC was reflecting. Reflecting was being thoughtful and critical about teaching and seeking feedback from peers and students. The clearest examples of reflection were the author's weekly class journals. Typical reflection topics included how the class was forming as a group, individual and group assessment of their learning, and material to discuss during the next class. An instructor's comment accurately captured reflecting. "I always review and update my objectives, and attempt to visit my 'Gestalt' or schema of where my content fits into the professional program" (C. Gulas, personal communication, October 19, 2006). Reflecting consisted of tracking where students were, currently are, and where they are going while adjusting the curriculum to meet their needs (instructor planning notes). Preparing and reflecting emerged as the beginning and end of EC, whereas modeling was the component that connected EC together.

Modeling comprised of teaching students to become meta-cognitive and demonstrating dynamic learning strategies (pacing yourself, being curious, being enthusiastic, and embracing the learning process) to enhance how they learn (Tinnesz et al., 2006). For example, the author constantly asked the students to think about their learning, what they were having difficulty with, and how they were connecting what they were learning to other aspects of their life. Moreover, modeling was demonstrating appropriate interactions in class and providing a safe environment to share ideas. Quotes from the student evaluations accurately illustrated modeling. "I think some strengths of this course are that the instructor really cares about our learning;" "The collaboration and engagement of our class;"

"The class environment was not too threatening. The professor was approachable;" and "The classroom felt safe to talk in." Modeling was putting preparation and reflection into practice and completing the process of systematically investigating the teaching process.

Interconnected with preparing, reflecting, and modeling were aspects of EC

Interconnected with preparing, reflecting, and modeling were aspects of EC that were not as easily observable and included personality traits, counselor training, and teaching philosophy. that were not as easily observable and included personality traits, counselor training, and teaching philosophy. For example, personality traits influenced the style of instruction and student interaction. Counselor training emphasized a value in Carl Rogers (1951) and the common factors (Hubble, Duncan, \& Miller, 1999) that produced a supportive, nonjudgmental atmosphere and a belief in the strengths of the students. The instructor's teaching philosophy provided a belief that student aptitude is time needed to learn and master a task rather than a relative constant trait of a person's possible achievement. The balance of preparing, reflecting, and modeling together with personality, counselor training, and teaching philosophy formed the essence of engaging conversationally. Moreover EC adds to the middle range theory of mutual engagement (Kiener, 2007) by gaining a deeper understanding of the instructor's role in facilitating engagement in the learning process. 


\section{Engaging Conversationally as a Pedagogical Tool}

Throughout the research process, the principles of action research continually reoccurred in the data at both a macro and micro level. At a macro level the research was conducted with the principles of action research and the scholarship of teaching and learning; an issue/concern to be investigated, plan of action, implementation of the plan, outcome evaluation, and, if necessary, a new plan (Stringer, 2007). At a slightly smaller level, a cyclical pattern emerged as a major component of EC; preparing, reflecting, and modeling by the instructor. Finally at the micro level, the pattern of inquiry was evident in the ongoing assessment of each student. A pattern of inquiry tracked and focused on how students were asking questions of content and thinking about how material was being connected. For example, written and oral assessments were evaluated against course objectives and future assessments were developed based on the progression of the students.

It is from the emergence and recognition of EC as an ongoing cyclical pattern of inquiry that establishes EC as a pedagogical tool; an ongoing pattern of inquiry that includes preparation, reflection,
It is from the emergence and recognition of EC as an ongoing cyclical pattern of inquiry that establishes EC as a pedagogical tool; an ongoing pattern of inquiry that includes preparation, reflection, and modeling. and modeling. Systematically employing EC can be seen as one method that can be used by the instructor to assess teaching and student understanding. It is plausible to believe that most instructors reflect on instruction; however, it is also plausible to believe that most instructors could benefit from a more systematic procedure. As previously stated, action research provides a method to determine an issue, collect and analyze data, and implement findings. Less formal methods of reflection include colleagues observing the teaching process and asking students what went well and not well. Student evaluations are possibly the most common form of feedback and can also be the most biased. Students can give appropriate feedback but also provide skewed accounts if disgruntled. Collecting multiple sources of data can reveal a more accurate reflection of teaching. EC emerged empirically from the data as an ongoing systematic cyclical pattern that emphasized inquiry and resulted in a richer understanding of the teaching and learning process.

\section{Discussion}

Analysis of the data revealed EC as an ongoing cyclical pattern of inquiry that included preparing, reflecting, and modeling. Interconnected in the pattern of inquiry were personality traits, counselor education, and teaching philosophy. Engaging conversationally emerged as one method to better understand how to facilitate and sustain an atmosphere of engagement in learning, while the systematic nature of EC benefited pedagogical design and student assessment. Although a deeper understanding of engagement was achieved, the research raised further questions.

\section{Engaging Conversationally and Mutual Engagement}

A grounded theory analysis of a rehabilitation counseling practicum class revealed mutual engagement and comfortability as conditions that promoted learning (Kiener, 2007). That analysis primarily focused on students and their ability to think about and develop learning. EC integrates into the theory by adding valuable insight on the instructor's role in facilitating and sustaining engagement in the learning process. EC can provide a method to systematically reflect and improve one's teaching. In addition, EC presents a means for assessing student progress. As a whole, mutual engagement and engaging conversationally provides a lens to 
examine how students and instructors engage in the learning process with emphasis on group dynamics, cognitive and affective development, and systematic inquiry.

From a pedagogical perspective, EC provides a process for continued analysis at a micro and macro level. At the micro level, preparing, reflecting, and modeling for each class enables instruction to be focused on individuals and the class as a whole; and it embraces the fluidity needed to make adjustments. At the macro level, EC allows for reflection of past courses, preparation for the future, and sets the stage for modeling systematic reflection. Continued research on engagement will only increase its applicability as a substantive theory and its usefulness as a pedagogical tool.

\section{Implications for a Broader Audience}

The relevancy of engaging conversationally and the scholarship of teaching and learning are applicable in all disciplines and can be easily implemented with action research. Inherent in engaging conversationally, scholarship of teaching and learning, and action research are principles to improve one's work. Perhaps the greatest benefit is in the flexibility of action research. Action research can be used to examine an instructor's questioning

\author{
Inherent in engaging \\ conversationally, \\ scholarship of teaching and \\ learning, and action \\ research are principles to \\ improve one's work.
}

technique, curriculum review, and or to develop a middle range theory of how students learn. All organizations, as well as individuals coming in contact with these professionals, would benefit from this approach.

EC can be applied to other disciplines by illustrating the specific application of knowledge required to become a professional. For example, EC can provide a method to understand how one thinks and acts in a certain profession. All disciplines would benefit from students learning what it means to be an effective practitioner. EC could be used to study and develop curriculum that creates effective practitioners. Adding the principles of the scholarship of teaching and learning to EC makes the work public and open for critique, improvement, and adoption across disciplines.

\section{Ethical Considerations and Limitations of the Study}

As educators, the ability to be self-reflective practitioners is crucial to professional and student development (Kraft, 2002). Perhaps more important is the ability to teach and model how to critique and improve one's practice. Kraft recommended a greater awareness for instructors to study their teaching and question belief systems that guide their practice. Paralleling this recommendation are the principles and values of the scholarship of teaching and learning that arguably rest on the capabilities of teachers to recognize and embrace the mission of systematically studying their teaching. Accomplishing these principles requires instructors to rigorously research their teaching as they do in their professional domains and to go public with their results for others to critique and build upon (Huber \& Hutchings, 2005). It is feasible to believe that teachers who embrace this philosophy are responding ethically to the call of beneficence.

\section{Conclusion}

Although there are many benefits to this study, it is also important to point out its limitations. Perhaps the greatest limitation is the theory's developmental stage. Further studies are needed to move the theory past middle range to substantive and then to formal. The first step in this progression is to examine mutual engagement and engaging conversationally in courses that differ in content and size. It is also important to note that this theory is only one way to engage 
students in their learning and not the only way. A strict adherence to this theory would contradict the principles of action research and restrict critical inquiry of one's teaching. Additional insight would be gained from other researchers implementing engagement into their course design and documenting their results. It is feasible to believe that systematic inquiry is the greatest strength of this theory.

Engaging conversationally emerged out of the need to investigate how an instructor facilitated and sustained an atmosphere of engagement in learning. What was revealed was a systematic process of inquiry that included personality traits, counselor education, and teaching philosophy. While the recognition of engagement as a positive impact on learning is not new and may even seem novel, the development of engagement as a pedagogical tool and as a systematic procedure for inquiry is paramount and warrants additional investigation. Continued use and investigation of EC will only refine and enhance its utility across disciplines and provide a richer understanding of the teaching and learning process.

\section{References}

Ahuna, K. H. \& Tinnesz, C.G. (2006). Methods of inquiry: Applied critical thinking $\left(2^{\text {nd }}\right.$ ed). Dubuque, Iowa:Kendall/Hunt.

Blythe, T. \& Associates. (1998). The teaching for understanding guide. San Francisco: Jossey-Bass.

Corey, S. M. (1952). Action research by teachers and the population sampling problem. Journal of Educational Psychology, 42(6), 331338.

Glaser, B.G. (1978). Theoretical sensitivity. Mill Valley, California: The Sociology Press.

Grushka, K., McLeod, J.H., \& Reynolds, R. (2005). Reflecting upon reflection: theory and practice in one Australian university teacher education program. Reflective Practice, 6(2), 239-246.

Heppner, P. P., Kivlighan, D.M., \& Wampold, B.E. (1999). Research design in counseling ( $2^{\text {nd }}$ ed). Belmont, CA: Brooks/Cole Wadsworth.

Hirschy, A. S., \& Wilson, M.E. (2002). The sociology of the classroom and its influence on student learning. Peabody Journal of Education, 77(3), 85-100.
Hubble, M.A., Duncan, B.L., \& Miller, S.D. (Eds.). (1999). The heart and soul of change: What works in therapy. Washington, DC: American Psychological Association.

Huber, M. \& Hutchings, P. (2005). The advancement of learning building the teaching commons. San Francisco, California: Jossey-Bass.

Llorens, M. (1994). Action research: Are teachers finding their voice?. The Elementary School Journal, 1, 3-10.

Jezewski, M. A. (1995). Evolution of a grounded theory: Conflict resolution through culture brokering. Advances in Nursing Science, 17(3), 14-30.

Kiener, M. S. (2007). Scholarship of teaching in rehabilitation counseling practicum. Rehabilitation Education, 21, 169-178.

Koch, L. C. \& Arhar, J.M. (2002).

Action research in rehabilitation counseling intern supervision.

Rehabilitation Education, 16(2), 165177.

Koch, L. C., Arhar, J.M., \& Wells, L.M. (2000). Educating rehabilitation counseling students in reflective practice. Rehabilitation Education, 14(3), 255-268.

Kraft, N. P. (2002). Teacher research as a way to engage in critical reflection: A case study. Reflective Practice, 3(2), 175-189. 
Magnuson, S. \& Norem, K. (2002). Reflective counselor education and supervision: An epistemological declaration. Reflective Practice, 3(2), 167-173.

McKinney,J. P., McKinney, K.G., Franiuk, R., \& Schweitzer, J. (2006). The college classroom as a community impact on student attitudes and learning. College Teaching, 54(3), 281-284.

Rogers, C. R. (1951). Client-centered therapy: Its current practice, implications, and theory. Boston: Houghton Mifflin.

Rovai, A. P. (2001). Building classroom community at a distance: A case study. Educational Technology, Research and Development, 49(4), 33-48.

Schlosser, L. Z. \& Gelso, C.J. (2005). The advisory working alliance inventory-advisor version: Scale development and validation. Journal of Counseling Psychology, 52(4), 650-654.
Schlosser, L. Z. \& Gelso, C.J. (2001). Measuring the working alliance in advisor-advisee relationships in graduate school. Journal of Counseling Psychology, 48(2), 157167.

Schrader, D. E. (2004). Intellectual safety, moral atmosphere and epistemology in college classrooms. Journal of Adult Development, 11(2), 87-101.

Strauss, A. \& Corbin, J. (1998). Basics of qualitative research techniques and procedures for developing grounded theory ( $2^{\text {nd }}$ ed.). Thousand Oaks: Sage Publications.

Stringer, E.T. (2007). Action research ( $3^{\text {rd }}$ ed.). Los Angeles: Sage Publications.

Tinnesz, C. G., Ahuna, K. H., \& Author, M. (2006). Toward college success: Internalizing active and dynamic strategies. College Teaching, 54(4), 302-306.

Michael Kiener, PhD, is an assistant professor at Maryville University. He is on the advisory council of Maryville University's Center for Teaching and Learning focusing on action research and the scholarship of teaching and learning. He has published articles on career decision making, learning strategies, counseling pedagogy, and action research. 